\title{
Литолого-фациальная характеристика петинских отложений Воронежской антеклизы
}

\author{
(C2021 А. В. Милаш ${ }^{凶}$, А. В. Черешинский \\ Воронежский государственный университет, \\ Университетская пл. 1, 394018 Воронеж, Российская федерация
}

\begin{abstract}
Аннотация
Bведение: Отложения петинской свиты верхнего франа впервые были описаны В. Н. Крестовниковым в 1925 г. С тех пор они изучались рядом авторов, но образования свиты в пределах всей Воронежской антеклизы остались недостаточно изученными. Этот пробел и восполняет настоящая статья. Методика и фактический материал: Основным методом исследований отложений был литологофациальный анализ. При построении фациальных карт использованы разрезы нескольких сотен скважин.

Результаты и обсуждение: На основании подробной литологической характеристики основных типов петинских образований Воронежской антеклизы показано, что их формирование практически на всей исследуемой территории происходило в мелководно-морских условиях со слабой и средней активностью гидродинамического режима. У границ отсутствия отложений, в центральной и юговосточной частях исследуемой территории петинские отложения накапливались в прибрежно-морских условиях с различной гидродинамикой среды, от слабой до высокой, с песчано-глинистым осадконакоплением.

Заключение: Для петинского времени характерно развитие песчано-глинистых образований прибрежно-морских фаций на юге и юго-востоке исследуемой территории, которые к северу и северовостоку сменяются прибрежно-морскими глинисто-карбонатными отложениями.

Ключевые слова: девон, петинское время, терригенные породы, карбонатные породы, фациальный анализ.
\end{abstract}

Источник финансирования: Исследование выполнено при финансовой поддержке РФФИ в рамках научного проекта № 18-35-00115 мол_а.

Для цичтирования: Милаш А. В., Черешинский А. В. Литолого-фациальная характеристика петинских отложений Воронежской антеклизы // Вестник Воронежского государственного университета. Серия: Геология. 2021. №2. С. 22-28. DOI: https://doi.org/10.17308/geology.2021.2/3485

\section{Введение}

Отложения петинской свиты верхнего франа Воронежской антеклизы (ВА), мощностью до 31 м, распространены севернее пшироты г.г. Курск - Воронеж (рис. 1), трансгрессивно, со следами размыва, залегая на подстилающих их семилукских образованиях. Нижняя ее граница, как правило, выражена литологически и на каротажных диаграммах. Исключение представляет северная часть Воронежской антеклизы, где морские карбонатно-глинистые отложения петинского возраста залегают на сходных семилукских осадках. Южная граница распространения петинских образований имеет эрозионный характер [1-4].

Контент доступен под лицензией Creative Commons Attribution 4.0 License.

凶 Милаш Алексей Васильевич, e-mail: pirit86@yandex.ru 
Петинские отложения впервые были описаны В. Н. Крестовниковым в 1925 г., как базальная часть воронежских слоев, в стратотипическом разрезе на правом берегу р. Дон у с. Петино Воронежской области. Д. В. Наливкин в 1930 г. отделил петинские слои от воронежских, и придал им значение горизонта [3].

С петинского времени начинается новый крупный этап осадконакопления, сопровождавшийся структурной перестройкой региона и излиянием базальтов. Для горизонта в целом характерна сильная фациальная изменчивость как по площади, так и по разрезу.

В стратотипическом разрезе у с. Петино, ниже г. Воронежа, на правом берегу Дона, свита представлена внизу разнозернистыми кварцевыми песчаниками серого, белого, желтоватого цветов, содержащими гравий в нижний части. В верхней части разреза - песками средне- и мелкозернистыми, содержащими прослои каолиновых глин и кварцевых алевролитов, значительное количество углефицированных растительных остатков, остатки рыб и редкие раковинки остракод. Пески по всему разрезу имеют разнонаправленную косую слоистость, характерную для прибрежно-морских отложений. Последние распространены вдоль большей части южной границы развития петинского горизонта [4].

Основное внимание в статье посвящено проблеме реконструкции условий осадконакопления в петинское время на территории ВА.

\section{Методика фациальных построений}

Составление фациальной карты петинского времени проводилось в два этапа: подготовительный и составительский. В подготовительный этап вёлся сбор и систематизация всего фактического материала, подготовка его для составления карты. В составительский этап в определенной последовательности и в соответствии с фактическим материалом отрабатывался наиболее оптимальный вариант модели карты. Проводились следующие операции по составлению карты: 1. Нанесение на карту точек выбранных разрезов и мощности (полной или неполной) отложений изучаемого стратиграфического интервала; 2. Построение карты изопахит - линий равных мощностей; 3. Выделение фациальных зон.

Метод литолого-фациального исследования заключался в комплексном изучении отложений, отражающих особенности седиментации. Изучались структурно-текстурные признаки, характеризующие динамику среды и способ осадконакопления, состав фауны, наличие авто- и аллохтонного органического вещества, свидетельствующего о глубине бассейна и близости континента, состав минеральных компонентов, отражающих источники сноса материала. Затем определялась принадлежность литотипов пород к группам фаций: I-III - морские; IV - переходные. В каждой из групп выделялись фациальные обстановки по типу гидродинамического режима в бассейне седиментации (для морских образований) и по типам обстановок (для переходных отложений). Полные разрезы с установленными кровлей и подошвой стратиграфического подразделения (горизонта), принимались за 100\%. Затем проводился подсчет процентного соотношения мощностей различных литотипов в разрезах. При этом породы, слагающие менее $10 \%$ всего разреза, на картах не показаны. Границы резких изменений состава и типов пород в плане и в разрезе соответствуют границам фациальных зон. Литология пород показывается соответствующим знаком, фациальная обстановка - римской цифрой. Последовательность полос снизу-вверх в элементарном разрезе отвечает хронологической последовательности наслоения пород. В соответствии с этим давались названия зон: первые цифры обозначают фациальную обстановку, буквы - гидродинамический режим. При чередовании нескольких литотипов в разрезе, между цифровыми индексами, обозначающими фациальные обстановки, ставится тире. В случае невозможности установления однозначного генезиса различных типов отложений, используется двойной индекс [4-7].

\section{Фациальные обстановки петинского времени Воронежской антеклизы}

Петинские осадки накапливались в прибрежно- и мелководно-морских зонах с различной гидродинамикой среды (рис. 1), обусловленной близостью берега и глубиной морского дна.

Большую часть площади в петинское время занимала мелководно-морская зона со спокойным гидродинамическим режимом (IIA), которая простиралась от г. Брянска до г. Кирсанова и имела ширину от 50 до 100 км. На западе территории, в районе Брянска, Орла и Малоархангельска, данная зона представлена глинами тёмно-серыми до чёрных, песчаными, иногда с примесью углефицированных растительных остатков. В отдельных разрезах глины интенсивно ожелезнены. В центральной части Воронежской антеклизы, в районе г. Ельца и г. Липецка, разрез данной фациальной зоны представлен глинами от серых и зеленовато-серых до темно-бурых, плотными, аргиллитоподобными, с горизонтальной слоистостью, преимущественно карбонатными. Характерны горизонты, обогащенные железистыми оолитами и углефицированной органикой. В северо-восточной части антеклизы, в районе Мичуринска и Тамбова, разрез представлен глинами серыми, зеленовато-серыми, алевритистыми, в различной степени карбонатными, в которых отмечается большое количество оолитов сидерита и пиритизированные растительные остатки. Общая мощность глин в данной зоне доходит до 28.5 м на северо-востоке антеклизы.

Южнее г. Малоархангельска, у границ выклинивания петинских отложений, выделяется зона ІІАБ, сложенная алевритами. Алевриты светло-серые и желтовато-серые, глинистые, пятнами и полосами ожелезнены.

На востоке и юго-востоке исследуемой территории располагались мелководно-морские зоны с переменным 


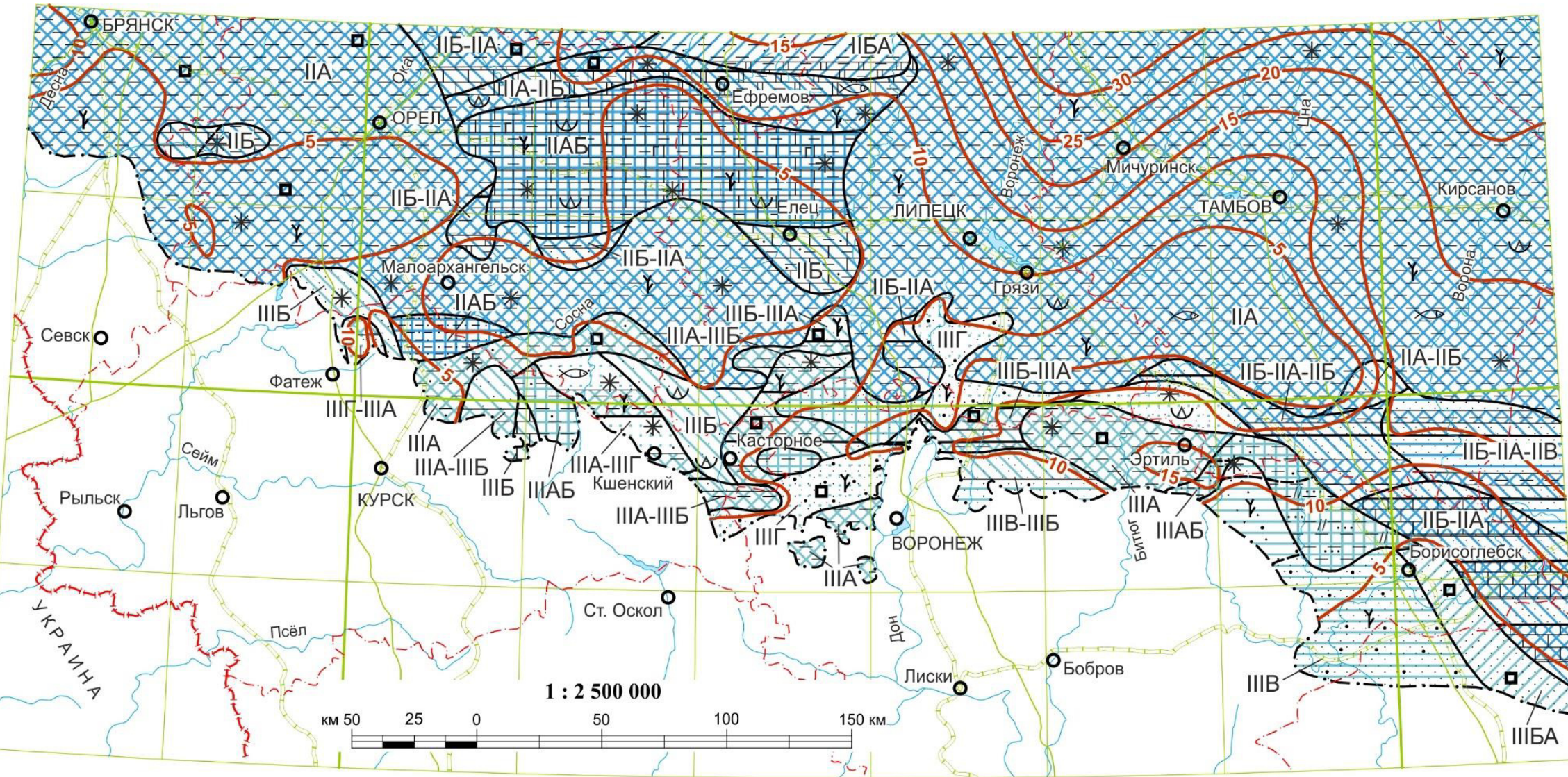

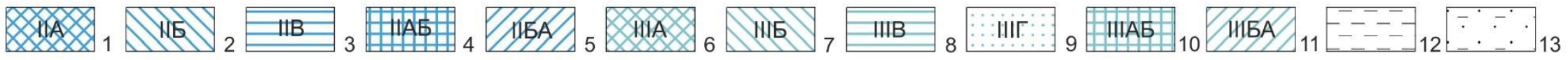

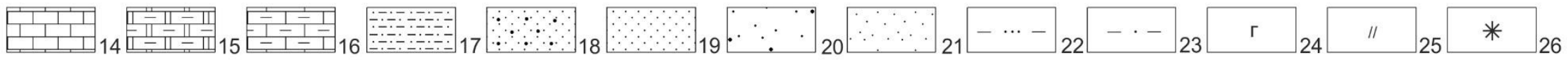

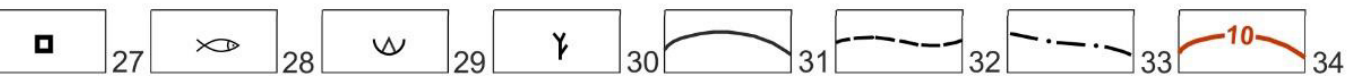

Рис. 1. Фациальная карта петинского времени. Мелководно-морские фациальные обстановки с активностью гидродинамического режима: 1 - слабой, 2 -средней, 3 - высокой, 4 - слабой и средней, с преобладанием слабой, 5 - слабой и средней, с преобладанием средней; прибрежно-морские фациальные обстановки с активностью гидродинамического режима: 6 - слабой, 7 - средней, 8 - высокой, 9 - переменной, 10 - слабой и средней, с преобладанием слабой, 11 - слабой и средней, с преобладанием средней; 12 - глины, 13 - глинь запесоченные, 14 - известняки, 15 - известняки доломитизированные, глинистые, 16 - мергели, 17 - алевриты, 18 - песчаники разнозернистые, 19 - песчаники тонко-, мелко-, среднезернистые, 20 - пески разнозернистые, 21 - пески мелко-, среднезернистые, 22 - примесь алевритового материала, 23 - примесь песчаного материала, 24 - примесь глауконитового материала, 25 - слюдистость, 26 - ожелезнение, 27 - включения пирита, 28 - остатки рыб, 29 - брахиоподы, 30 - растительные остатки, 31 - границы фациальных зон, 32 - границы фатиапьных пппзон 33 - гпаниша пасппостпанения птппжений 34 - изппахиты 
[Fig. 1. Facie map of the Voronezh anteclise. Petino period. Legend: Shallow sea facies with hydrodynamic regime: (1) weak, (2) medium, (3) high, (4) weak and medium, with a predominance of weak, (5) weak and medium, with a predominance of medium; coastal-sea facies with hydrodynamic regime: (6) weak, (7) medium, (8) high, (9) variable, (10) weak and medium, with a predominance of weak, (11) weak and medium, with a predominance of medium; (12) clays, (13) sanded clays, (14) limestones, (15) dolomitized limestones, clay, (16) marls, (17) siltstones, (18) sandstones of various grains, (19) fine-, medium - grained sandstones, (20) sand of various grains, (21) fine- medium - grained sandstones, (22) admixture of siltstone material, (23) admixture of sand material, (24) admixture of glauconite material, (25) mica, (26) ferruginization, (27) pyrite inclusions, (28) fish remains, (29) brachiopods, (30) plant remains, (31) boundaries of facies zones, (32) boundaries of facies subzones, (33) boundary of sediment distribution, (34) isopachites.]

гидродинамическим режимом (ІІБ-ІІА, ІІБ-ІІА-ІІБ). Здесь разрез представлен аргиллитоподобными глинами, известняками, песчаниками и алевролитами. Песчаники мелко-, среднезернистые светло-серые, реже пестроокрашенные полевошпат-кварцевые и слюдисто-полевошпат-кварцевые массивные горизонтально-слоистые с глинистым, глинисто-сидеритовым, кальцитово-глинистым цементом, с циркон-ставролитдистеновой ассоциацией, с включениями железистых оолитов в кровле слоя. Алевролиты светло-зеленоватосерые слюдистые плитчатые неравномерно глинистые с большим количеством пиритизированных растительных остатков. Глины аргиллитоподобные алевритистые серые, табачно-зеленые гидрослюдистые плитчатые с углефицированными растительными остатками. Известняки органогенно-обломочные криноидные, криноидно-брахиоподовые, светло-серые, глинистые. Общая мощность отложений в данных зонах не превышает $16 \mathrm{M}$.

В центральной части исследуемой территории выделяются зоны, сложенные мергелями (зоны ІІБ и ІІАБ). Мергели серые и зеленовато-серые, плотные, с горизонтальной слоистостью и тонкоплитчатой отдельностью. В районе г. Ельца в мергелях зоны ІІБ присутствуют зерна глауконита. Общая мощность мергелей в данных зонах не превышает 7 м.

На крайнем севере рассматриваемой территории, севернее зон ІІБ и ІІАБ, развиты органогенно-обломочные доломитизированные известняки, переслаивающиеся с аргиллитоподобной карбонатной глиной (зоны ІІА-ІІБ и ІІ). Известняки серые и зеленовато-серые, микрозернистые, глинистые, доломитизированные, содержащие фауну брахиопод, остракод и криноидей. Глины от серых и зеленовато-серых до темно-бурых, плотные, аргиллитоподобные, с горизонтальной слоистостью, преимущественно карбонатные. Общая мощность петинских отложений в данных фациальных зонах доходит до 12.5 м.

Вдоль границы выклинивания петинских отложений, от г. Курска до г. Борисоглебска, выделяются ряд фациальных зон прибрежно-морского генезиса со средне-активным гидродинамическим режимом (средне- и разнозернистые пески), средне- и слабым (средне-мелкозернистые пески и глины), слабым (глины), переменным (переслаивание глин, алевролитов, песков с разной гранулометрией, мергелей, известняков).

В районе г. Курска выделяется зона ІІІГ, сложенная разнозернистыми, в основном грубозернистыми, зеленовато-серыми песками с включением гравия и гальки [8]. Южнее данной зоны располагается зона IIIA, сложенная зеленовато-серыми мергелями, мощностью до $10 \mathrm{M}$.

Северо-восточнее г. Курска выделяются фациальные зоны IIIA и IIIA-ІІІБ, сложенные глинами аргиллитоподобными, от желтовато-серых до коричневатозеленых, жирными на ощупь, иногда интенсивно ожелезненными, песчанистыми, с примесью углефицированных растительных остатков и алевритами серыми, зеленовато-серыми, в различной степени глинистыми. Обычно глины преобладают над алевритами. Общая мощность петинской свиты здесь изменяется от 3 до $17 \mathrm{м}$.

В районе г. Кшень петинские отложения формировались в прибрежно-морских условиях со слабой, средней и высокой активностью гидродинамического режима (зоны IIIА, ІІІБ, ІІІА-ІІІГ, ІІІАБ). Разрез в них представлен песками с подчинёнными прослоями алевритов, глин и песчаников. Пески светло-серые и серые, иногда буровато-желтые вследствие ожелезнения, разнозернистые, кварцевые, в разрезах сменяются от тонко-мелкозернистых до грубозернистых с гравийными зернами кварца. В песках наблюдаются прослои глинистого песчаника, алевритов, песчаных и алевритистых глин. В нижней части разреза отмечается прослой черной аргиллитоподобной глины, плотной, обогащенной углефицированной органикой, с гнездами землистых агрегатов пирита. Общая мощность петинской свиты в данных зонах доходит до 18 м.

Юго-восточнее пгт. Касторное выделяется зона IIIГ, представленная грубозернистыми кварцевыми песчаниками, иногда переходящими в гравелиты. Песчаники от светло-серых до серых, для них характерна косая однонаправленная слоистость. Выше по разрезу они сменяются тонко-среднезернистыми песками, которые выше переходят в песчанистые глины, в которых отмечается большое количество мелких оолитов железа. Мощность отложений не превышает 10 м.

Севернее вышеописанной фациальной зоны ІІІГ располагаются зоны ІІІАБ и ІІІА-ІІІБ, сложенные песками, песчаниками, глинами с прослоями алевролитов. Пески и песчаники от светло-серых до темно-серых, иногда буровато-серые и буровато-желтые вследствие ожелезнения, разнозернистые, от тонкозернистых до крупнозернистых, при преобладании мелко- среднезернистых. Песчаники преимущественно кварцевые, часто переполнены мелкими железистыми оолитами (размером до 1 мм), вплоть до железисто-оолитовых песчаников. В них отмечаются многочисленные пиритизированные и углефицированные растительные остатки. Данные образования неравномерно глинистые, от неглинистых до сильно глинистых, песчаники рыхлые, преобладает карбонатно-глинистый цемент, 
реже встречается железистый, сидеритовый и фосфатный. Глины от серых и зеленовато-серых до темно-бурых и коричневато-бурых, плотные, аргиллитоподобные, преимущественно некарбонатные. Отмечаются горизонты, обогащенные железистыми оолитами и углефицированной органикой. Характерны тонкие прослои серых и темно-серых, тонко-мелкозернистых песчаников и алевролитов.

К северу от г. Воронежа выделяется зона ІІІВ-ІІІБ, разрез которой представлен песками и песчаниками общей мощностью до 9 м. Породы белые, желтые, серые, реже буровато-серые, кварцевые, разнозернистые: в основании грубозернистые до гравийных, вверх по разрезу средне- и тонкозернистые; местами косослоистые, с прослоями глин и алевролитов; содержат большое количество углефицированного растительного детрита и обломков рыб, часто наблюдаются скопления железистых оолитов.

В районе г. Эртиль располагается фациальная зона IIIA, представленная глинами серыми, с голубоватозеленоватым оттенком, алевритистыми, горизонтально слоистыми, с тонкими прослоями кварцевых песчаников. В основании разреза глины углистые, с темно-серой до черной окраски. Мощность отложений в данной зоне доходит до $11.2 \mathrm{м}$.

Юго-восточнее г. Эртиль выделяется зона IIIB, разрез которой слагают песчаники с белесо-серой, охристо-желтой и буровато-красной, пятнистой окраской, кварц-полевошпатового состава с глинистым цементом, каолинизированные, разно-грубозернистые, крепко сцементированные, общей мощностью до 6.5 м.

Севернее вышеописанной фациальной зоны расположены зоны ІІІАБ и ІІІБА, сложенные песчаниками и алевритами. Песчаники мелко-, среднезернистые светло-серые, реже пестроокрашенные полевошпаткварцевые и слюдисто-полевошпат-кварцевые массивные горизонтально-слоистые с глинистым, глинистосидеритовым, кальцитово-глинистым цементом, с циркон-ставролит-дистеновой ассоциацией, с включениями железистых оолитов в кровле слоя. Алевриты светло-зеленовато-серые, слюдистые, неравномерно глинистые с большим количеством пиритизированных растительных остатков. Общая мощность отложений в данных фациальных зонах не превышает 15 м.

\section{Заключение}

Анализ фациальной карты и схем осадконакопления (рис. 2) показывает, что формирование петинских отложений практически на всей территории Воронежской антеклизы происходило, в основном, в мелководно-морских условиях со слабой и средней активностью гидродинамического режима, с характерным карбонатно-глинистым типом осадков. У границ отсутствия отложений, в центральной и юго-восточной частях исследуемой территории петинские отложения накапливались в прибрежно-морских условиях с различной гидродинамикой среды, от слабой до высокой, с песчано-глинистым осадконакоплением. Максимальное разнообразие фациальных обстановок характерно для южной и юго-восточной части исследуемой территории. Море наступало с востока, северо-востока, а снос терригенного материала шел с юга и запада.
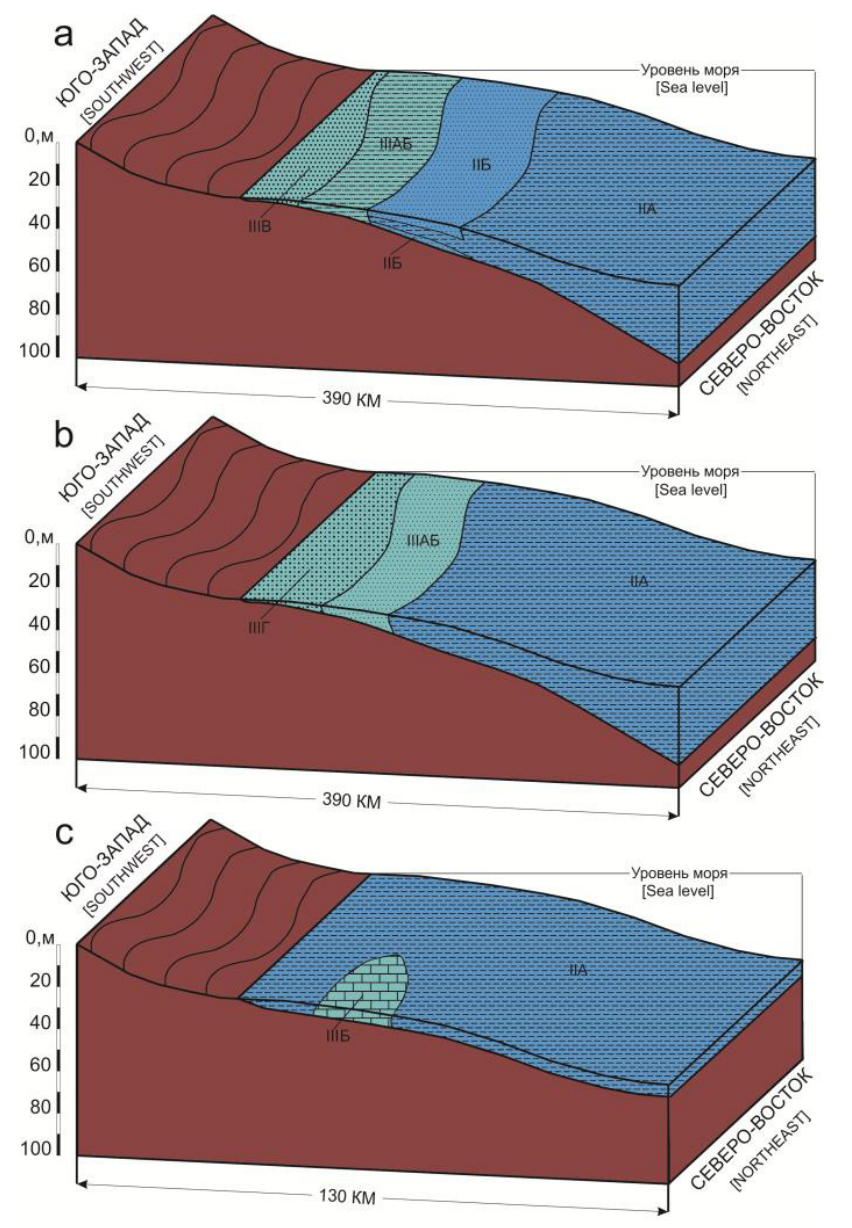

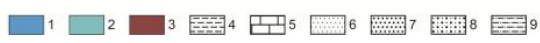

Рис. 2. Схемы седиментогенеза в петинское время для юговосточной (a), центральной (b) и северо-западной (c) части Воронежской антеклизы: 1 - мелководно-морские фациальные обстановки; 2 - прибрежно-морские фациальные обстановки; 3 - область сноса; 4 - аргиллитоподобные глины; 5 - известняки; 6 - пески мелко-среднезернистые; 7 - пески крупнозернистые; 8 - пески разнозернистые; 9 - алевриты.

[Fig. 2. Schemes of sedimentogenesis in Petino period for the south-eastern $(a)$, central $(b)$, and north-western $(c)$ parts of the Voronezh anteclise. Legend: (1) - shallow marine facies environments; (2) - coastal marine facies environments; (3) - alimentation zone; (4) - clay-stones; (5) - limestones; (6) - fine-medium grained sands; (7) - coarse-grained sands; (8) - mixed-grained sands; (9) aleurites.]

Конфликт интересов: Авторы декларируют отсутствие явных и потенциальных конфликтов интересов, связанных с публикацией настоящей статьи.

\section{ЛИТЕРАТУРА}

1. Савко А. Д., Мануковский С. В., Мизин А. И, Бурыкин В. Н., Бартенев В. К., Окороков В.А., Бабкин В. Ф. Литология и фации донеогеновых отложений Воронежской антеклизы. Труды научно-исследовательского института геологии: Воронеж, Изд-во Воронеж. гос. ун-та. Вып. 3, 2001. $201 \mathrm{c}$. 
2. Савко А. Д. Геология Воронежской антеклизы. Труды научно-исследовательского института геологии: Воронеж, Изд-во Воронеж. гос. ун-та. Вып. 12, 2002. 165 с.

3. Кононова Л. И., Овнатова Н. С., Ржосницкая М. А., Родионова Г. Д., Умнова В. Т., Федорова Т. И. Девон Воронежской антеклизы и Московской синеклизы. М. : Комитет РФ по геологии и использованию недр, 1995. $265 \mathrm{c}$.

4. Савко А. Д., Мануковский С. В., Мизин А. И., Бурыкин В. Н., Бартенев В. К. Объяснительная записка к атласу фациальных карт Воронежской антеклизы. Труды научно-исследовательского института геологии: Воронеж, Изд-во Воронеж. гос. ун-та. Вып. 20, 2004. 107 с.

5. Милаш А. В., Савко А. Д. Литология девонских отложений юго-востока Воронежской антеклизы. Труды научно-исследовательского института геологии: Воронеж, Изд-во Воронеж. гос. ун-та. Вып. 100, 2017. $131 \mathrm{c.}$

6. Виноградов А. П., Наливкин В. Д., Ронов А. Б., Хаин В. Е. Атлас литолого-палеогеографических карт Русской платформы и ее геосинклинального обрамления. М.-Л.: Государственное научно-техническое издательство литературы по геологии и охране недр, 1961. С. 65-69.

7. Hallam A. Facies interpretation and the stratigraphic record. W. H. Freeman and Co. Oxford. 1981. 304 pp.

8. Государственная геологическая карта Российской Федерации. Масштаб 1:200 000. Серия Воронежская. Лист М-37I (Курск). Объяснительная записка. - М.: МФ ВСЕГЕИ, $2009.137 \mathrm{c}$

GENERAL AND REGIONAL GEOLOGY

UDC 551.83(470.32)

DOI: https://doi.org/10.17308/geology.2021.2/3485

Received: 15.05 .2021

Accepted: 20.05.2021

Published online: 30.06 .2021

\title{
Lithofacies characteristics of the Petino deposits in the Voronezh anteclise
}

\author{
C2021 A. V. Milash ${ }^{凶}$, A.V. Chereshinskiy \\ Voronezh State University, \\ 1 Universitetskaya pl., Voronezh 394018, Russian Federation
}

\begin{abstract}
Introduction: Sedimentary rocks of the Upper Frasnian Petino suite were first described by V. N. Krestovnikov in 1925. Since then, they have been studied by a number of authors. However, the formations within the whole Voronezh anteclise remain understudied. The aim of this article is to fill this gap.

Methodology: The deposits were studied using lithofacies analysis. The facie maps were based on the sections of several hundred wells.

Results and discussion: The results of a detailed lithological characterisation of the main types of Petino deposits in the Voronezh anteclise demonstrated that the formation of the studied sediments practically all over the studied territory occurred under shallow-marine conditions with the weak and medium activity of the hydrodynamic regime. At the borders of the areas lacking deposits in the central and south-eastern parts of the studied area, Petino deposits accumulated in the coastal-marine conditions with different hydrodynamics of the environment, from weak to high, with a sand-clay sedimentation.

Conclusions: The Petino period is characterised by the development of sand-clay formations of coastalmarine facies in the south and south-east of the studied area, which to the north and north-east are replaced by coastal-marine carbonate-argillaceous sediments.

Keywords: Devonian, Petino period, terrigenous rocks, carbonate rocks, facies analysis.

Funding: The study was supported by the Russian Foundation for Basic Research, project no. 18-35-00115 mol_a.
\end{abstract}

The content is available under Creative Commons Attribution 4.0 License.

Alexey V. Milash, e-mail: pirit86@yandex.ru

Вестник Воронежского государственного университета. Серия: Геология. 2021, № 2, 22-28 
For citation: Milash A. V., Chereshinskiy A.V. Lithofacies characteristics of the Petino deposits in the Voronezh anteclise. Vestnik Voronezhskogo gosudarstvennogo universiteta. Seriya: Geologiya - Proceedings of Voronezh State University. Series: Geology, 2021, no. 2, pp. 22-28. DOI: https://doi.org/10.17308/geology.2021.2/3485

Conflict of interests: The authors declare the absence of obvious and potential conflicts of interest related to the publication of this article.

\section{REFERENCES}

1. Savko A. D., Manukovski S. V., Mizin A. I., Burikin V. N., Bartenev V. K., Okorokov V. A., Babkin V.F. Litologia I facii doneogenovih onlozhenii Voronezhskoi anteklizi. [Lithologi and facies of the Voronezh anteclise preneogene deposites]. Trudy Nauchno-issledovatel'skogo Instituta Geologii [The work of the Research Institute of Geology], Voronezh, VSU Publ., 2001, vol. 3, 201 p. (In Russ.)

2. Savko A. D. Geologia Voronezhskoi anteklizi. [Geology of the Voronezh Antecline]. Trudy Nauchno-issledovatel'skogo Instituta Geologii [The work of the Research Institute of Geology], Voronezh, VSU Publ., 2002, vol.12, 165 p. (In Russ.)

3. Kononova L. I., Ovnatova N. S., Rzhosnitskaya M. A., Rodionova G. D., Umnova V. T., Fedorova T. I. Devon Voronezhskoi anteklizi i Moskovskoi sineklizi. [The Devonian of the Voronezh anticline and the Moscow synklin]. Moscow, Komitet RF po geologii i ispolzovanii nedr, 1995, 265 p. (In Russ., abstract in Eng)

4. Savko A. D., Manukovski S. V., Mizin A. I., Burikin V. N., Bartenev V. K. Objasnitelnaja zapiska $k$ atlasu facialnih kart Voronezhskoi anteklizi. [Explanatory memorandum to the facies maps atlas of the Voronezh anteclise]. Trudy Nauchno-issledovatel'skogo Instituta Geologii [The work of the Research Institute of Geology], Voronezh, VSU Publ., vol. 20, 2004, 107 p. (In Russ., abstract in Eng)

5. Milash A. V., Savko A. D. Litologia devonskih onlozheniy ugo-vostoka Voronezhskoy anteclizi. [Lithologi of the Devonian deposits of the southeast of the Voronezh antecline]. Trudy Nauch-no-issledovatel'skogo Instituta Geologii [The work of the Re-search Institute of Geology], Voronezh, VSU Publ., vol. 100, 2017, 131 p. (In Russ., abstract in Eng) 6. Vinogradov A. P., Nalivkin V. D., Ronov A. B., Hain V.E. Atlas litologopaleograficheskih kart Russkoy platformi $i$ ee geosinklinalnogo obramlenia. [Atlas of the lithological-paleogeo-graphical maps of the Russian platform and its geosynclinals framing]. M-L. State Scientific and Technical Publishing House of Literature on Geology and Mineral Protection, 1961, pp. 65-69. (In Russ.)

7. Hallam A. Facies interpretation and the stratigraphic record. W. H. Freeman and Co. Oxford. 1981.304 p.

8. Gosudarstvennaya geologicheskaya karta Rossiiskoi Federatsii. Masshtab 1:200 000. List M-37-I (Kursk). Ob"yasnitel'naya zapiska. [State Geological Map of the Russian Federation. Scale 1: 200,000. Sheet M-37-I (Kursk). Explanatory note]. Saint Petersburg: VSEGEI publ., 2009. 137 p.
Милаш Алексей Васильевич - к. г.-м. н., доцент, Воронежский государственный университет, Воронеж, Российская Федерация; E-mail: pirit86@yandex.ru;

ORCID https://orcid.org/0000-0002-2956-3021

Черешинский Алексей Васильевич - к. г.-м. н., доцент, Воронежский государственный университет, Воронеж, Российская федерация; E-mail: vsu31022@mail.ru; ORCID https://orcid.org/0000-0003-0697-3551

Авторы прочитали и одобрили окончательный вариант рукописи.
Alexey V. Milash - PhD in Geol.-Min., associate professor, Voronezh State University, Voronezh, Russian Federation; E-mail: pirit86@yandex.ru;

ORCID https://orcid.org/0000-0002-2956-3021

Alexey V. Chereshinskiy - PhD in Geol-Min., Associate Professor, Voronezh State University, Voronezh, Russian Federation; E-mail: vsu31022@mail.ru;

ORCID https://orcid.org/0000-0003-0697-3551

Authors have read and approved the final manuscript. 